\title{
Cardiac biomarkers in patients with epilepsy.
}

\author{
1. FCPS, \\ MRCP (Medicine \& Neurology) \\ Consultant Neurologist \\ Sheikh Khalifa Bin Zaid Hospital/ \\ Poonch Medical College Rawlakot. \\ 2. FCPS \\ Associate Professor Medicine \\ Sheikh Khalifa Bin Zaid Hospital/ \\ Poonch Medical College Rawlakot. \\ 3. MRCP \\ Assistant Professor Medicine \\ Sheikh Khalifa Bin Zaid Hospital/ \\ Poonch Medical College Rawlakot \\ 4. FCPS \\ Assistant Professor Medicine \\ Sheikh Khalifa Bin Zaid Hospital/ \\ Poonch Medical College Rawlakot \\ 5. FCPS \\ Senior Registrar Medicine \\ Sheikh Khalifa Bin Zaid Hospital/ \\ Poonch Medical College Rawlakot. \\ 6. FCPS \\ Assistant Professor Cardiology \\ Sheikh Khalifa Bin Zaid Hospital/ \\ Poonch Medical College Rawlakot. \\ Correspondence Address: \\ Dr. Sadia Hanif \\ Consultant Neurologist \\ Sheikh Khalifa Bin Zaid Hospital/ \\ Poonch Medical College Rawlakot. \\ drsadeya21@gmail.com \\ Article received on: \\ 19/09/2020 \\ Accepted for publication: \\ $17 / 11 / 2020$
}

\begin{abstract}
Sadia Hanif', Shazia Siddiq ${ }^{2}$, Jhangir Zaib ${ }^{3}$, Syed Azhar Ali ${ }^{4}$, Rabia Tahir $^{5}$, Nisar Ahmad ${ }^{6}$
ABSTRACT... Objective: To determine the frequency of deranged cardiac biomarkers and associated socio-demographic factors among patients of epilepsy presenting at our hospital. Study Design: Cross-sectional study. Setting: Department of Medicine, Sheikh Khalifa Bin Zyed Al-Nyhan Hospital Rawalakot. Period: August 2019 to September 2020. Material \& Methods: We evaluated 85 consecutive patients who presented at Department of Medicine, Sheikh Khalifa Bin Zyed Al-Nyhan hospital. Cardiac Biomarkers (Troponin I, CK-MB and pro-BNP) and EKG were requested in all patients. The questionnaire used for interview consisted of demographic details and disease related parameters (duration of epilepsy and number of antiepileptic drugs). Results: Out of 85 patients included in the study, $35(41.2 \%)$ were male while $45(58.8 \%)$ were female. Out of these 85 patients of epilepsy, $15(17.6 \%)$ had one or more cardiac biomarker positive while $70(82.4 \%)$ had no change in ECG or any positive cardiac biomarker. All ECG changes were non-specific. After applying the logistic regression, we found that long duration of illness and poly-pharmacy had significant association with the presence of positive cardiac biomarkers among the patients of epilepsy. Conclusion: Less than $1 / 5^{\text {th }}$ of the patients with epilepsy had positive cardiac biomarkers or ECG changes in our study. Patients with longer duration of epilepsy or those whose epilepsy has been managed with more than one drug were found more at risk of having abnormal cardiac biomarkers in our target population.
\end{abstract}

Key words: $\quad$ Cardiac Biomarkers, Epilepsy, Socio-Demographic Factors.

Article Citation: Hanif S, Siddiq S, Zaib J, Ali SA, Tahir R, Ahmad N. Cardiac biomarkers in patients with epilepsy. Professional Med J 2021; 28(7):1033-1038. https://doi.org/10.29309/TPMJ/2021.28.07.6160

\section{INTRODUCTION}

Epilepsy have been a common condition diagnosed among patients of all age groups in all parts of the world. ${ }^{1}$ It has also been included in the mental health gap program launched by WHO for the low and middle income countries. ${ }^{2}$ Epilepsy though primarily has been a seizure disorder, yet involve the whole body and may predispose the individual toward various other health related conditions which may sometime be life threatening and need immediate intervention from a multidisciplinary team in addition to the treating neurologist or medical specialist. ${ }^{3,4}$

\section{Sudden Unexpected Death in Epilepsy (SUDEP)} has been one of the rare but lethal complication seen among the patients suffering from epilepsy. Multiple causes may contribute to this unexplained phenomenon but still no exact cause could be figured out in this context. Respiratory problems, abnormal rhythm of heart, and altered cerebral blood flow have been some of the causes which were found on postmortem examinations and related to SUDEP among patients of epilepsy. 5,6 Still a lot of work has been under progress to find the exact cause or factors related to SUDEP in order to prevent this lethal condition.

As cardiac events may be responsible for SUDEP so there may be a need to screen patients of epilepsy for cardiac biomarkers. If not all, at least the high risk patients may be screened from this aspect. Szabó et al. published a study in 2019 from USA regarding cardiac biomarkers related to epilepsy. They came up with the conclusion that QT and QTc intervals were significantly prolonged among the epileptic patients as compared to controls highlighting the fact that this might be possible cause of SUDEP among such patients. ${ }^{7}$ Another similar study performed by Brotherstone 
et al. in 2009 regarding lengthening of QTc interval during epileptic seizure. They conducted EEG and ECG simultaneously on epileptic patients and concluded that Significant lengthening of corrected QT cardiac repolarization time occurred during some epileptic seizures in this study. Prolonged corrected QT may have a role in sudden unexplained death in epilepsy. ${ }^{8}$ Burghaus et al. in 2011 studied effect of epileptic seizures on cardiac function and summarized that multidisciplinary team is necessary for management of epilepsy as seizures may disrupt rhythm of heart and cause arrhythmias or ictal asystole which may be responsible for SUDEP. Prolong QT interval was also proposed as possible cause of cerebral channelopathy. Multiple factors were found interlinked between seizures and cardiac abnormalities which may be responsible for worst outcome among such patients. $^{9}$

Local data is limited regarding this aspect of epilepsy. This is one of the reasons epilepsy has been part of those diseases included in mhGap for low and middle income countries like ours. Epidemiological data has been available for patients of epilepsy and mortality related to this disease as well ${ }^{10}$ but causes other than seizures have not been evaluated and published in detail for local population. This study was planned with the aim to assess the frequency of deranged cardiac biomarkers and associated sociodemographic factors among patients of epilepsy presenting at our hospital.

\section{MATERIAL \& METHODS}

This cross-sectional study was conducted at the department of Medicine, Sheikh Khalifa Bin Zayd Al-Nyhan Hospital Rawlakot from August 2019 to September 2020. Sample size was calculated by WHO Sample Size Calculator by using population prevalence proportion of SUDEP as $0.12 \% .{ }^{11}$ Non probability Consecutive sampling technique was used to gather the sample. All patients between the age of 18 and 60 with epilepsy diagnosed by a consultant medical specialist according to 2010 International League Against Epilepsy (ILAE) Commission report were included in the study. ${ }^{12}$ Exclusion criteria were the patients with psychogenic non epileptic fits, cardiac abnormalities prior to epilepsy, mental retardation or learning disability, dystonias and psychiatric disorders. Patients who were pregnant or breast feeding, had B12 or folate deficiency, had recent surgery, had NSAIDs abuse or any autoimmune disorder those who were using illicit drugs or those whose follow up was not possible were also excluded from the study.

Ethical review board committee of the hospital was approved this study (1492/CIV/2020). Written informed consent was taken from all the potential participants of this study before the start of study after complete description of the study. Patients of epilepsy fulfilling the above mentioned inclusion and exclusion criteria coming to medical OPD at Sheikh Khalifa Bin Zayd Al-Nyhan Hospital Rawalakot were included in the study. Venous blood was taken from the participants between 9 and 11 a.m. after 12 hours of fasting. Troponin $\mathrm{I}, \mathrm{CK}-\mathrm{MB}$ and pro-BNP were assessed via an automated analyzer. Variables in the study included age, gender, duration of epilepsy, and poly-pharmacy. Duration of illness was classed as disease lasting for less than or more than five years. Use of more than one drug for epilepsy was regarded as poly-pharmacy. Normal levels of troponin I were below $0.04 \mathrm{ng} / \mathrm{ml}$, CK-MB were 3 to $5 \%$ (percentage of total CK) or 5 to 25 $\mathrm{IU} / \mathrm{L}$, while pro-BNP were less than $450 \mathrm{pg} / \mathrm{mL}$ for patients under age 50 and less than $900 \mathrm{pg} /$ $\mathrm{mL}$ for patients age 50 and older. ${ }^{13,14}$ ECG was performed on all the patients and interpreted by consultant cardiologist.

Characteristics of participants and the distribution of the cardiac markers abnormalities were described by using the descriptive statistics. Participants were resulted by categorical compared by presence and absence of cardiac biomarkers abnormalities. Chi-square was used to determine between-group variances in categorical correlates. Binary logistic regression analysis was done to evaluate the relationship of age, gender, duration of epilepsy and polypharmacy with the presence of cardiac biomarkers abnormalities. Differences between groups were considered significant if $p$-values were less than 
or equal to 0.05 .

\section{RESULTS}

Out of 85 patients included in the study, 35 $(41.2 \%)$ were male while 50 (58.8\%) were female. Mean age of the patients was $38.25 \pm 6.943$ years. Table-l shows the characteristics of patients of epilepsy included in the study. Out of these 85 patients of epilepsy, 15 (17.6\%) had one or more cardiac biomarker positive while 70 (82.4\%) had no change in ECG or any positive cardiac biomarker. All ECG changes were non-specific. Table-Il showed that chi-square analysis revealed that long duration of illness and poly-pharmacy had significant association with the presence of positive cardiac biomarkers among the patients of epilepsy ( $p$-value<0.05). After applying the logistic regression (Table-III) this association was confirmed and these two parameters were found significantly related to positive cardiac biomarkers while age of the patients and gender did not show any such association ( $p$-value $>0.05$ ).

\begin{tabular}{|c|c|}
\hline $\begin{array}{l}\text { Age (years) } \\
\text { Mean + SD } \\
\text { Range (min-max) }\end{array}$ & $\begin{array}{c}38.25 \pm 6.943 \\
18 \text { years-58 years }\end{array}$ \\
\hline $\begin{array}{l}\text { Gender } \\
\text { Male } \\
\text { Female }\end{array}$ & $\begin{array}{l}35(41.2 \%) \\
50(58.8 \%)\end{array}$ \\
\hline $\begin{array}{l}\text { Abnormal Cardiac Biomarkers } \\
\text { Troponin I } \\
\text { CK-MB } \\
\text { pro-BNP } \\
\text { Electrocardiogram }\end{array}$ & $\begin{array}{c}03(3.5 \%) \\
05(5.8 \%) \\
02(2.3 \%) \\
10(11.7 \%)\end{array}$ \\
\hline $\begin{array}{l}\text { Presence of Polypharmacy } \\
\text { No } \\
\text { Yes }\end{array}$ & $\begin{array}{l}48(56.5 \%) \\
37(43.5 \%)\end{array}$ \\
\hline
\end{tabular}

\section{DISCUSSION}

Epilepsy has been one of those conditions which if detected in time and well investigated may be managed well with limited impact on overall quality of life. ${ }^{2}$

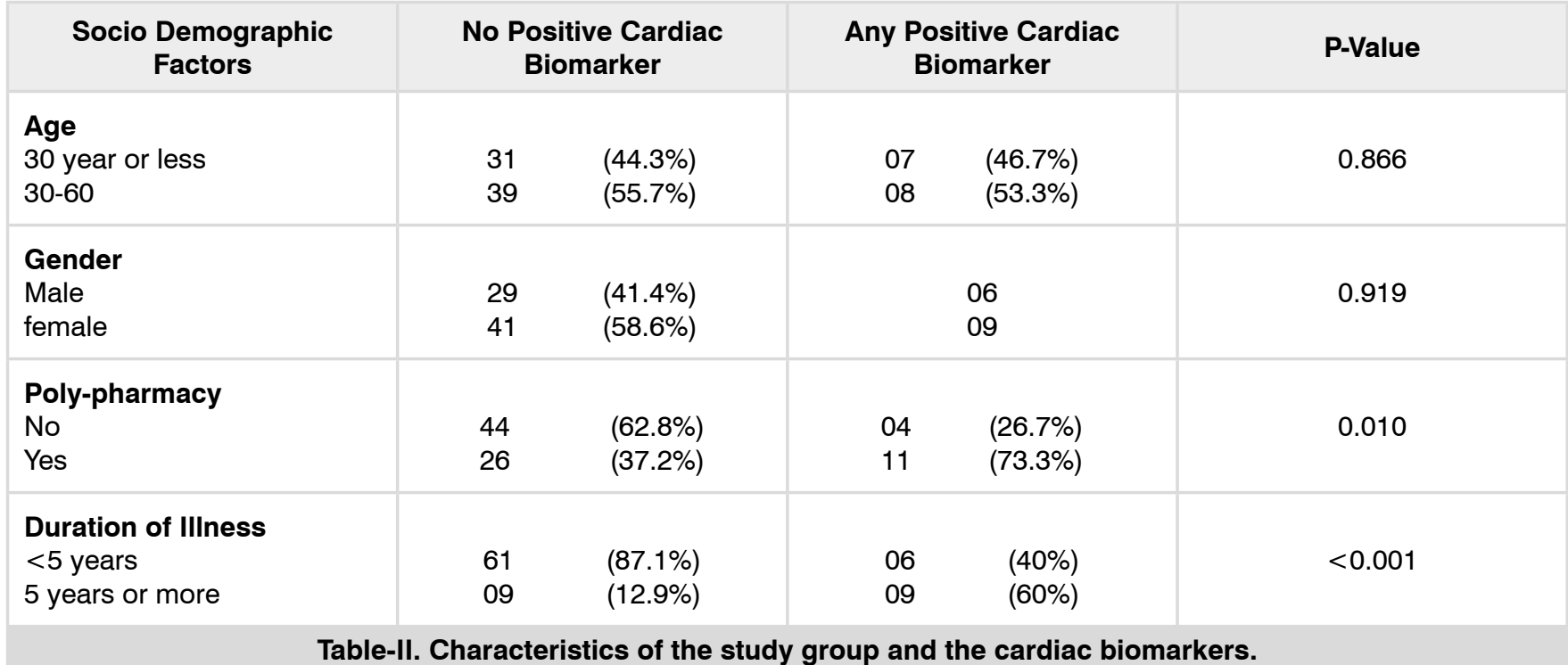

\begin{tabular}{|c|c|c|c|c|}
\hline & \multirow{2}{*}{ P-Value } & \multirow{2}{*}{ Odds Ratio } & \multicolumn{2}{|c|}{ Confidence Interval } \\
\hline & & & Lower & Upper \\
\hline Age(ref. is 30 years or less) & 0.292 & 0.465 & 0.111 & 1.935 \\
\hline Gender (ref. is male) & 0.756 & 1.250 & 0.305 & 5.130 \\
\hline Poly-pharmacy (ref. is no Poly-pharmacy) & 0.023 & 5.089 & 1.252 & 20.689 \\
\hline
\end{tabular}

Table-III. The correlated factors relating to presence of deranged cardiac biomarkers among the patients of epilepsy: The binary logistic regression analysis. 
Recent surgical options have also revolutionized the management aspect of this chronic condition especially the focal seizures. ${ }^{12}$ Seizure is such a multi-system event that it has impact on overall physiology of the body and if this phenomenon keeps on occurring and remains unchecked may cause threatening complications. ${ }^{5}$ Antiepileptic drug's though play a vital role in control of epilepsy, yet have certain adverse effects which may need to be kept in mind as these medications may have to be administered for years. Newer anti-epileptics lack data on safety aspects therefore careful monitoring should be carried out regularly if patient is on any newer drug. ${ }^{12}$ All these factors may predispose the individual towards various kinds of serious issues including cardiac involvement.

Alehan et al. ${ }^{15}$ in 2009 studied elevated CK-MB levels and plasma brain-type natriuretic peptide concentrations following convulsive seizures in children and adolescents and came up with the findings that CK-MB mass and BNP at the 12th hour were higher than those obtained on the 7 th day ( $p<0.05$ and $p<0.001$, respectively). Children with seizures had increased levels of CK-MB mass and BNP $12 \mathrm{~h}$ after seizure than control subjects $(p<0.05$ and $p<0.001$, respectively). The results of electrocardiography (ECG) recordings, which were obtained up to 30 min after seizure activity, were completely normal in patients with seizure..$^{15} 5.8 \%$ of the patients had raised CK-MB levels while $2.3 \%$ had raised BNP levels among our study participants which was quite considerable.

Leung et al. ${ }^{16}$ in 2006 tried to find out the link between ictal bradyarrhythmia, ictal asystole, and SUDEP among the patients suffering from epilepsy. They concluded that decreased heart rate leading to arrhythmia may be possible cause of SUDEP but it was not consistently found in all the patients. Ictal asystole was another finding related to SUDEP coined by them..$^{15} 10$ (11.7\%) of patients had abnormal ECG findings among our study participants but they were non-specific and were not clearly indicative of any definitive pathology.
Variation in heart rate leading to cardiac arrhythmias during or after seizures contributing to sudden unexplained death has been studied by Jeppesen et al. in $2014 .{ }^{17}$ They concluded that there was marked increase in the parasympathetic activity during the period preceding the fatal seizures, compared with values measured 1 day and 7 months before, and also higher than the pre-ictal values in a group of 10 patients with GTCS without SUDEP. The duration of the QTC interval was short $(335-358 \mathrm{msec}) .{ }^{17}$ Heart rate was not studied in our study and patients were not observed during or after the seizures therefore very few patients showed cardiac abnormalities and that too nonspecific.

de la Garza et al. ${ }^{18}$ in 2019 published a study with objective to evaluate autonomic differences, including heart rate $(\mathrm{HR})$, heart rate variability (HRV) and corrected QT-duration (QTC) between two epileptic (EB1, EB2) and one control (CB) baboon. They came up with the conclusion that heart rate and QTC interval was altered in cases of epilepsy as compared to controls and that might be one of the reasons for sudden unexplained death in these patients. 15 (17.6\%) patients had either raised troponin I or BNP or altered ECG in our study participants. More studies with longitudinal design may be required to look for any relationship of these markers with SUDEP.

There were number of limitations in our study. Patients were not followed up for long to look for long term outcome among patients with abnormal cardiac markers. Specific effect of anti-epileptic medications was not correlated with presence of abnormal cardiac biomarkers. Specific relationship of these abnormalities was not studied with recent EEGs or seizures.

\section{CONCLUSION}

Less than $1 / 5^{\text {th }}$ of the patients with epilepsy had positive cardiac biomarkers or ECG changes in our study. Patients with longer duration of epilepsy or those whose epilepsy has been managed with more than one drug were found more at risk of having abnormal cardiac biomarkers in our target population.

Copyright $\odot 17$ Nov, 2020. 


\section{REFERNCES}

1. Kim DW, Lee SK. Headache and epilepsy. Journal of Epilepsy Research. 2017; 7(1):7-15. doi:10.14581/ jer.17002.

2. Humayun A, Haq I, Khan FR, Azad N, Khan MM, Weissbecker I. Implementing mhGAP training to strengthen existing services for an internally displaced population in Pakistan. Global Mental Health. 2017; 4(1):e6. doi:10.1017/gmh.2017.1.

3. Huff JS, Murr N. Seizure. [Updated 2020 Mar 20]. In: Stat Pearls [Internet]. Treasure Island (FL): Stat Pearls Publishing; 2020 Jan-. Available from: https://www.ncbi. nlm.nih.gov/books/NBK430765/.

4. InformedHealth.org [Internet]. Cologne, Germany: Institute for Quality and Efficiency in Health Care (IQWiG); 2006-. Epilepsy: Overview. 2016 Jan 13 [Updated 2019 Dec 5]. Available from: https://www. ncbi.nlm.nih.gov/books/NBK343313/.

5. Elmali AD, Bebek N, Baykan B. Let's talk SUDEP. Noro Psikiyatr Ars. 2019; 56(4):292-301. Published 2019 Sep 5. doi:10.29399/npa.23663.

6. Pathak SJ, Shah VB. Sudden Unexpected Death in Epilepsy (SUDEP) [Updated 2020 Jul 4]. In: Stat Pearls [Internet]. Treasure Island (FL): Stat Pearls Publishing; 2020 Jan-. Available from: https://www.ncbi. nlm.nih.gov/books/NBK559104/.

7. Szabó CÁ, Akopian M, González DA, de la Garza MA, Carless MA. Cardiac biomarkers associated with epilepsy in a captive baboon pedigree. Epilepsia. 2019; 60(11):e110-e114. doi: 10.1111/epi.16359. Epub 2019 Oct 8. PMID: 31592545; PMCID: PMC7054851.

8. Brotherstone R, Blackhall B, McLellan A. Lengthening of corrected QT during epileptic seizures. Epilepsia. 2010; 51(2):221-32. doi: 10.1111/j.15281167.2009.02281.x. Epub 2009 Sep 3. PMID: 19732135.

9. Burghaus L, Fink GR, Erdmann E, Müller-Ehmsen J. Kardiale Auswirkungen epileptischer Anfälle [Epileptic seizures: Effects on cardiac function]. Dtsch Med Wochenschr. 2011; 136(7):315-9. German. doi: 10.1055/ s-0031-1272530. Epub 2011 Feb 7. PMID: 21302206.

10. GBD 2016 Epilepsy Collaborators. Global, regional, and national burden of epilepsy, 1990-2016: A systematic analysis for the Global Burden of Disease Study 2016. Lancet Neurol. 2019; 18(4):35775. doi:10.1016/S1474-4422(18)30454-X.
11. May TW, Israel CW. Sudden unexpected death in epilepsy (SUDEP): Epidemiology, cardiac and other risk factors. Herzschrittmacherther Elektrophysiol. 2019; 30(3):274-86. German. doi: 10.1007/s00399-01900643-0. PMID: 31489492.

12. Manford M. Recent advances in epilepsy. J Neurol. 2017; 264(8):1811-1824. doi:10.1007/s00415-017-83942

13. Patibandla S, Gupta K, Alsayouri K. Cardiac Enzymes. [Updated 2020 Aug 14]. In: Stat Pearls [Internet]. Treasure Island (FL): Stat Pearls Publishing; 2020 Jan. Available from: https://www.ncbi.nlm.nih.gov/books/ NBK545216/

14. Basit $H$, Huecker MR. Myocardial infarction serum markers. [Updated 2020 Aug 15]. In: Stat Pearls [Internet]. Treasure Island (FL): Stat Pearls Publishing; 2020 Jan-. Available from: https://www.ncbi.nlm.nih. gov/books/NBK532966/.

15. Alehan F, Erol I, Cemil T, Bayraktar N, Ogüs E, Tokel K. Elevated CK-MB mass and plasma brain-type natriuretic peptide concentrations following convulsive seizures in children and adolescents: Possible evidence of subtle cardiac dysfunction. Epilepsia. 2009; 50(4):755-60. doi: 10.1111/j.15281167.2008.01793.x. Epub 2008 Oct 6. PMID: 19183225.

16. Leung $H$, Kwan $P$, Elger $C E$. Finding the missing link between ictal bradyarrhythmia, ictal asystole, and sudden unexpected death in epilepsy. Epilepsy Behav. 2006; 9(1):19-30. doi: 10.1016/j.yebeh.2006.05.009. Epub 2006 Jun 30. PMID: 16809068.

17. Jeppesen J, Fuglsang-Frederiksen A, Brugada R, Pedersen B, Rubboli G, Johansen P, et al. Heart rate variability analysis indicates preictal parasympathetic overdrive preceding seizure-induced cardiac dysrhythmias leading to sudden unexpected death in a patient with epilepsy. Epilepsia. 2014; 55(7):e6771. doi: 10.1111/epi.12614. Epub 2014 Apr 4. PMID: 24701979.

18. de la Garza MA, Poldiak D, Shade R, Salinas FS, Papanastassiou AM, Szabó CÁ. Cardiac changes in epileptic baboons with high-frequency microburst VNS therapy: A pilot study. Epilepsy Res. 2019; 155(3):106156. doi: 10.1016/j.eplepsyres.2019.106156. Epub 2019 Jun 12. PMID: 31284120; PMCID: PMC6684821. 


\begin{tabular}{|c|l|l|l|}
\hline \multicolumn{3}{|c|}{ AUTHORSHIP AND CONTRIBUTION DECLARATION } \\
\hline Sr. \# & \multicolumn{1}{|c|}{ Author(s) Full Name } & \multicolumn{1}{|c|}{ Contribution to the paper } & Author(s) Signature \\
\hline 1 & Sadia Hanif & $\begin{array}{l}\text { Study design \& Concept } \\
\text { data collection. } \\
\text { Drafting. }\end{array}$ \\
\hline 3 & Shazia Siddiq & Critical revisiting. \\
\hline 4 & Syed Azhar Ali & Data collection. \\
\hline 6 & Rabia Tahir & Data collection & \\
\hline
\end{tabular}

